\title{
Preparation and Characterization of Molybdenum Oxide Biochar Catalyst for Efficient Desulfurization Process
}

\author{
Riman Iㅁ, Ibrahim ML1,2*, Deris RRR ${ }^{1}$, Mokhtar WNAW ${ }^{3}$, Mastuli \\ MS1,2, Jawaid $\mathrm{AH}^{1}$ and Mansir N ${ }^{4,5}$ \\ ${ }^{1}$ School of Chemistry and Environment, Faculty of Applied Sciences, Universiti \\ Teknologi MARA, Malaysia \\ ${ }^{2}$ Centre of Nanomaterials Research, Institute of Science, Universiti Teknologi MARA, \\ Malaysia
}

${ }^{3}$ Centre for Advanced Materials and Renewable Resources, Faculty of Science and Technology, Universiti Kebangsaan Malaysia, Malaysia

${ }^{4}$ Department of chemistry, Federal University Dutse, Nigeria

${ }^{5}$ Catalysis Science and Technology Research Centre, Faculty of Science, Universiti Putra Malaysia, Malaysia

*Corresponding author: Mohd Lokman Ibrahim, School of Chemistry and Environment, Faculty of Applied Sciences, Universiti Teknologi MARA, 40450 Shah Alam, Selangor, Malaysia, Tel: +6016 5002195; Email: mohd_lokman@uitm.edu.my

\section{Abstract}

Producing low-sulfur commercial fuel became one of the concerns nowadays in order to curb the environmental pollution. Extensive studies were developed in refining crude oil industries such as oxidation-extraction method and adsorption techniques, which utilizes small amount of catalyst with low pressure and temperature yet effective and cost saving. In this study, activated carbon (AC) from empty fruit bunch EFB was successfully prepared and impregnated with molybdenum oxide $\mathrm{MoO}_{3}$ for removal of sulfur from sulfur-added oil. The prepared activated carbon-molybdenum oxide $\mathrm{AC} / \mathrm{MoO}_{3}$ was characterized by using Brunauer-Emmett-Teller (BET), field emission-scanning electron microscopy (FESEM), X-ray fluorescence (XRF), X-ray diffraction (XRD) and energy dispersive X-ray (EDX). Meanwhile, two-step sulfur removal was carried out by catalytic oxidative-extractive desulfurization (Cat-OEDS) method. The characterization of the chemically treated AC shows high surface area, pore size and pore volume which is $1575.5 \mathrm{~m}^{2} \mathrm{~g}^{-1}, 0.835 \mathrm{~cm}^{3} \mathrm{~g}^{-1}$ and $2.120 \mathrm{~nm}$ respectively. From the results obtained, the 15\% metal oxide molybdenum displays the highest sulfur removal by adsorption of $66.7 \%$ (500 ppm) and 51.12\% (800 ppm) while $97.96 \%$ (500 ppm) and $96.54 \%$ (800 ppm) sulfur reduction in the presence of oxidant TBHP and DMF as an extractant which the oxidation performed at $30^{\circ} \mathrm{C}$ while 


\section{Petroleum \& Petrochemical Engineering Journal}

extraction conducted on ambient temperature for 30 minutes of both processes. As conclusion, the prepared $\mathrm{AC} / \mathrm{MoO}_{3}$ derived from EFB promises as an excellent metal oxide catalyst for absorptive-oxidative-extractive sulfur removal from any sulfur contained fuels.

Keywords: Activated Caron; Empty fruit bunch; Molybdenum Oxide; Heterogeneous Catalyst; Desulfurization; Oxidative-extractive Desulfurization; Adsorption

\section{Introduction}

Nowadays, the usage of petroleum is directly increased due to the vast economic growth and the escalated number of vehicles. Basically, crude oil contained high number of hydrocarbon and other organic compound such as sulfur [1]. Upon fuel combustion, the release of sulfur oxide (SOx) and other poisonous gas such as carbon monoxide (CO) which hardly to degrade, thus in long-term it will contribute hazards towards the environment [2-4]. The combination of sulfur oxide with the atmosphere produces acidic rain and causes mass corrosion, killing the aquatic animals and plants.

As been reported in previous work removing of sulfur or known as desulfurization can be done either by adsorptive desulfurization [5,6], extractive desulfurization [7], bio-desulfurization [8], photocatalytic desulfurization [9], hydrodesulfurization [10] and oxidation desulfurization [11] techniques. However, the only common method like hydrodesulfurization (HDS) and oxidation desulfurization (ODS) are commonly applied. Basically, sulfur removal by HDS process requires high temperature and pressure, large amount of hydrogen and catalyst: making it a non-economic method. HDS effectively remove aliphatic sulfur compound like mercaptane, sulphide and disulphide. However, thiophenic sulfur compound cannot be removed by HDS [12]. Meanwhile, the ODS is an alternative of thiophenic sulfur compound removal, which operates under mild condition and low-cost method [13,14] Another alternative recommended method is adsorptive desulfurization (ADS). Operates at mild condition, which has high affinity towards the thiophenic sulfur compound and indeed the correct adsorbent is important to determine the efficiency of the process [15].

Activated carbon (AC) are commonly used as a support or adsorbent in ODS process, in fact it commercially available and can be synthesis. The unique characteristic such as large surface area, excellent electron conductivity, high porosity, and inert makes AC an excellent support catalyst which can be synthesis from many sources of residual such as sawdust [16], waste tire [17] and empty fruit bunch (EFB). This not only producing value-added material but also manufacturing greener catalyst support. Basically, EFB is the main biomass waste for Malaysia and Indonesia who are producing and exporting large amount of palm oil annually. It easily modifiable at specific condition to produce a stable AC which has high surface area and theoretically has great surface characteristics as absorbance and catalyst's support. In the field of catalysis development, introduction of support catalyst could improve catalytic activity, stability and selectivity [18]. From the previous study, metals could have excellent boost for desulfurization process and the common transition metals used as active site such as Co [6], Mo [10], Mn [15], Zn [19], Ni [20], Cr [21], Pd [22], Ti [23], Fe [24], $\mathrm{Cu}[25], \mathrm{W}$ [26] and $\mathrm{V}$ [27].

In this work, the main focus was to analyze the potential of impregnated $\mathrm{MoO}_{3}$ on $\mathrm{AC}$ derived from EFB as a catalytic absorbance in desulfurization process. The absorption followed by catalytic oxidative-extractive desulfurization (OEDS) processes were carried out to remove dibenzothiophene (DBT) as model sulfur compound from the sulfur added-model oil under different catalyst and active sites loading. It was believed that this research has high potential for development of low sulfur fuel.

\section{Experimental}

\section{Materials}

Ammonium molybdate tetrahydrate, $\left(\mathrm{NH}_{4}\right)_{6} \mathrm{Mo}_{7} \mathrm{O}_{24} .4 \mathrm{H}_{2} \mathrm{O}, 99 \%$, analytical grade reagent was purchased from QReC. Meanwhile, the potassium hydroxide, $\mathrm{KOH}$ and $\mathrm{N}, \mathrm{N}$-Dimethylformamide, DMF were obtained from R\&M Chemical and Chemiz, respectively. The solvent such as hydrochloric acid, $\mathrm{HCl}$, ethanol absolute, $\mathrm{CH}_{3} \mathrm{CH}_{2} \mathrm{OH}$ and isooctane were purchased from 


\section{Petroleum \& Petrochemical Engineering Journal}

Emsure chemical company. The tert-Butyl hydroperoxide (TBHP) (70\% solution in water) and dibenzothiophene (DBT) were supplied from Merck. All the chemicals were directly used without any purification process.

\section{Preparation of AC-derived EFB}

Readily carbonized empty fruit bunch (EFB) was grounded with $\mathrm{KOH}$ pallets of weight ratio 1:1, in order to increase the porosity of the carbon based EFB. Subsequently, the paste of EFB-KOH mixed was calcined at $800^{\circ} \mathrm{C}$ for $2 \mathrm{hr}$. The resulted of black powdered of carbon was rinse thoroughly with $1 \mathrm{M}$ hot $\mathrm{HCl}$ and hot distilled water until the $\mathrm{pH} 6 \sim 7$ and dried at $110^{\circ} \mathrm{C}$ to produce AC-derived EFB.

\section{Preparation of $\mathrm{AC} / \mathrm{MoO}_{3}$ Catalyst}

In this work, thermal co-precipitation method was used to synthesis the catalyst which was adopted from Saleh, et al. [6] and Abdullah, et al. [28] with slight modification. About $1 \mathrm{~g}$ of AC-EFB was dispersed in $25 \mathrm{~mL}$ of water-ethanol mixture $(3: 2 / \mathrm{v}: \mathrm{v})$ for 5 hours. To prepare $5 \%$ of $\mathrm{MoO}_{3}$ onto the structure of $\mathrm{AC}$, about $0.85 \mathrm{~g}$ of $\left(\mathrm{NH}_{4}\right)_{6} \mathrm{Mo}_{7} \mathrm{O}_{24} .4 \mathrm{H}_{2} \mathrm{O}$ was diluted with distilled water to form $0.1 \mathrm{M}$ metal solution, which subsequently added dropwise into the AC suspension followed by $\mathrm{pH}$ adjustment with $\mathrm{KOH}$ solution to basic $\mathrm{pH}$ 8-9. The mixture was stirred for 2 hours and aging for 12 hours followed by refluxed at $80^{\circ} \mathrm{C}$ for 6 hours. The catalyst formed was washed with ethanol and distilled water then further dried at $110^{\circ} \mathrm{C}$. The black powder was calcined at $900^{\circ} \mathrm{C}$ for 3 hours with temperature ramp $5^{\circ} \mathrm{C}$ min $^{-1}$ to produce $\mathrm{AC} / \mathrm{MoO}_{3}(5 \%)$ catalyst. This method was used to prepare the $10 \%, 15 \%$ and $20 \%$ of $\mathrm{MoO}_{3}$ on the structure of $\mathrm{AC}$-EFB and annoted as $\mathrm{AC} / \mathrm{MoO}_{3(\mathrm{x})}$, where ' $\mathrm{x}$ ' is the percentage of metal oxide loading.

\section{Characterization of $\mathrm{AC} / \mathrm{MoO}_{3}$ Catalyst}

The surface characteristics of the prepared catalyst was analysed by Brunauer-Emmett-Teller (BET) technique using nitrogen adsorption/desorption on BEL Japan Inc, Belsorp II. The structure pattern and phase crystallography of sample was characterized using X-Ray Diffraction (XRD) recorded at $2 \theta$ between $10^{\circ}$ and $80^{\circ}$ using the Malvern Panalytical diffractometer, X'Pert Pro, UK with the $\mathrm{Cu} K \alpha$ radiation operates at $40 \mathrm{kV}$ and $40 \mathrm{~mA}$ with $\lambda=1.5418 \AA$ Å. To study the morphology of particle, catalyst was examined using US Thermo Fisher Scientific, scanning electron microscope (SEM), Phenom XL. Thermo gravimetric Analyzer (TGA) using model SETARAM SETSYS Evolution 1750, US instrument was performed to understand the decomposition pattern of the functional group of the catalyst particles. Meanwhile, the X-ray fluorescence (XRF) conducted by using UK Malvern Panalytical, Epsilon 3XL Benchtop XRF Spectrometer for determination of $\mathrm{MoO}_{3}$ presence on the $\mathrm{AC}$ particles.

\section{Sulfur Removal by Adsorption and Oxidative- extractive Desulfurization}

The desulfurization activity of the catalyst was tested by mixing with $500 \mathrm{ppm}$ and $800 \mathrm{ppm}$ DBT in isooctane as model oil in the presence of oxidizing agent TBHP and extractant N,N-Dimethylformamide (DMF). The operating parameters such as oxidant-to-sulfur molar ratio, reaction time, reaction temperature, catalyst loading, catalyst dose-to-model oil and DMF-to-model oil ratio were at constant.

For adsorption process, $10 \mathrm{ml}$ model oil containing $500 \mathrm{ppm}$ sulfur was added and stirred with $0.1 \mathrm{~g}$ catalyst for 30 minutes at room temperature. The treated model oil was filtered afterwards and an aliquot of the filtered desulfurized oil was analyzed for sulfur content by gas chromatography with flame ionization detector (GC-FID).

In the other hand, for oxidation-extraction process, 10 $\mathrm{ml}$ of $500 \mathrm{ppm}$ sulfur in model oil, $0.1 \mathrm{~g}$ catalyst and tertbutyl hydroperoxide (TBHP) oxidant with oxidant to sulfur ratio of $3 \mathrm{~mol}(\mathrm{O} / \mathrm{S}=3)$ placed in a flask and stirred for 30 minutes at $50^{\circ} \mathrm{C}$. The oxidized model oil then further subjected for sulfur extraction by liquid-liquid extraction technique. In this process, catalyst was removed by filtration and the oxidized model oil was mixed with DMF with ratio $1: 1$ (v:v) and stirred vigorously for 30 minutes at ambient temperature and atmospheric pressure. The resultant extraction produces two separate layers of treated model oil and extractant where an aliquot of the treated oil was examined for sulfur content by gas chromatography with flame ionization detector (GC-FID).

\section{Sulfur Determination by GC-FID}

Analysis of DBT content was conducted by using Agilent 7890 gas chromatography flame ionization detector (GC-FID) equipped with HP-5MS capillary column $(30 \mathrm{~m} \times 0.250 \mathrm{~mm}, 0.25 \mu \mathrm{m}$ film thickness). The inlet and detector temperatures were set at $230^{\circ} \mathrm{C}$ and $250^{\circ} \mathrm{C}$ respectively. The column temperature retained for 0 min at $100^{\circ} \mathrm{C}$ followed by temperature risen to $180^{\circ} \mathrm{C}$

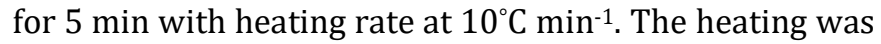
continued risen to $230^{\circ} \mathrm{C}$ and held for 5 min with heating 
rate $10^{\circ} \mathrm{C} \mathrm{min}^{-1}$. Flow rate of air, nitrogen and hydrogen were 350,30 and $30 \mathrm{~mL} \mathrm{~min}^{-1}$ respectively with injection volume of $1.0 \mu \mathrm{L}$. Determination of sulfur compound was calculated by using the [Equation 1];

$$
\frac{C i-C f}{C i} \times 100 \%
$$

Where:

$\mathrm{Ci}$ represents the initial concentration of sulfur Cf represents the amount of sulfur of treated model oil

\section{Results and Discussion}

\section{Characterization of The Catalyst}

The morphology of the prepared catalyst was characterized by FESEM. The images displayed in Figure 1(a - f) shows the non treated AC-EFB, KOH treated AC$\mathrm{EFB}, \mathrm{AC} / \mathrm{MoO}_{3}(5 \%), \mathrm{AC} / \mathrm{MoO}_{3}(10 \%), \mathrm{AC} / \mathrm{MoO}_{3}(15 \%)$ and $\mathrm{AC} / \mathrm{MoO}_{3}(20 \%)$, respectively. From the images, it was observed that there was pore enlargement after carbonized EFB was treated with $\mathrm{KOH}$ using 1:1 weight ratio. Averagely, the pore diameters before $\mathrm{KOH}$ treatment was about $9 \pm 2 \mathrm{~nm}$, after treated showing the increasing of pore diameter ranging from $9.5 \pm 2 \mathrm{~nm}$ to 11 $\pm 2 \mathrm{~nm}$. This is due to the chemical treatment by the $\mathrm{KOH}$ which commonly known as activation agent [29]. The chemically treated AC showing fine distribution of porous, this could improve the surface area, pore volume and pore size. Hence, theoretically can boost the absorption capability and also it can provide larger sites for the catalytic reaction.

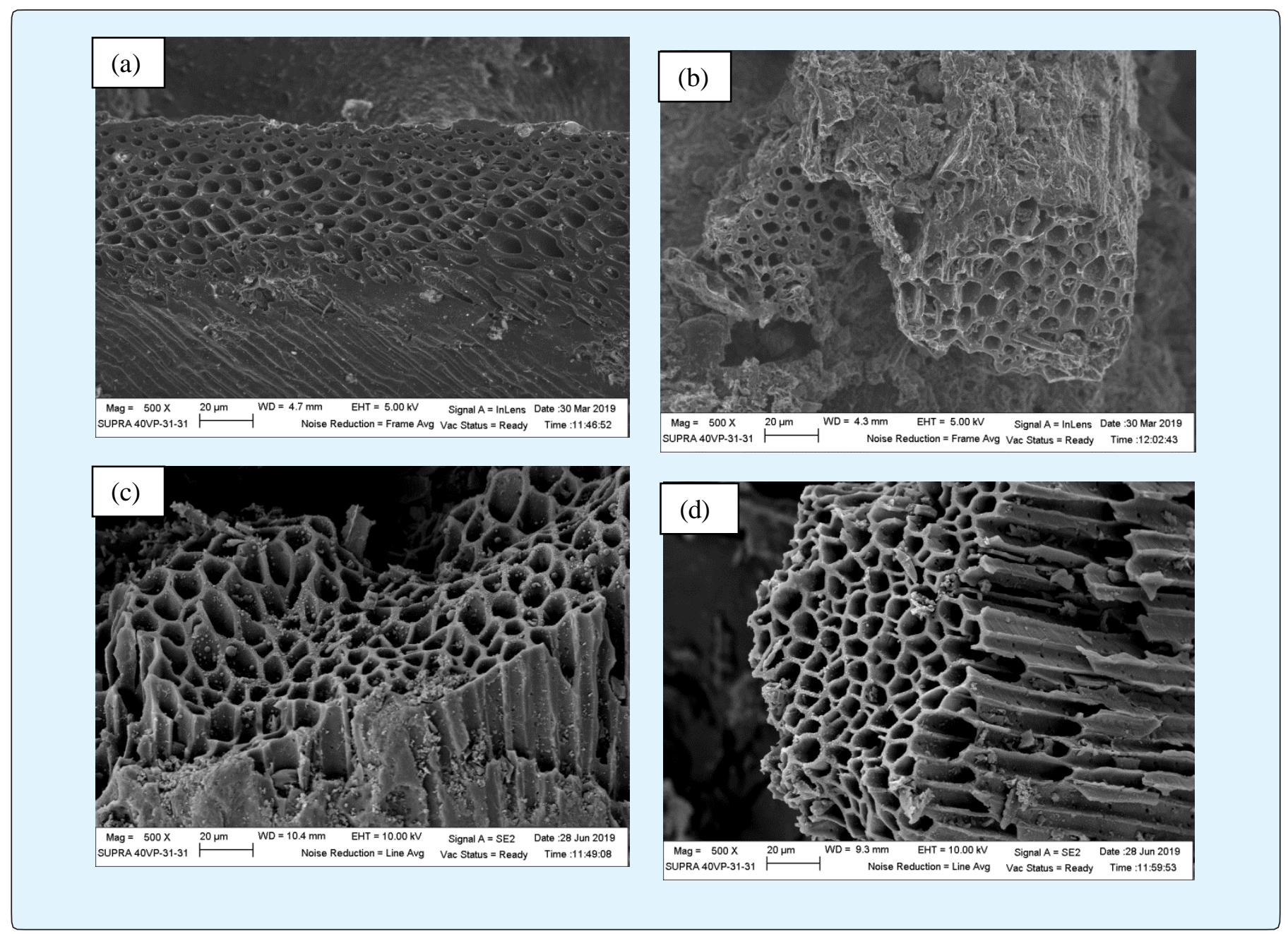

Ibrahim ML, et al. Preparation and Characterization of Molybdenum Oxide Biochar Catalyst for Efficient Desulfurization Process. Pet Petro Chem Eng J 2019, 3(5): 000204. 


\section{Petroleum \& Petrochemical Engineering Journal}
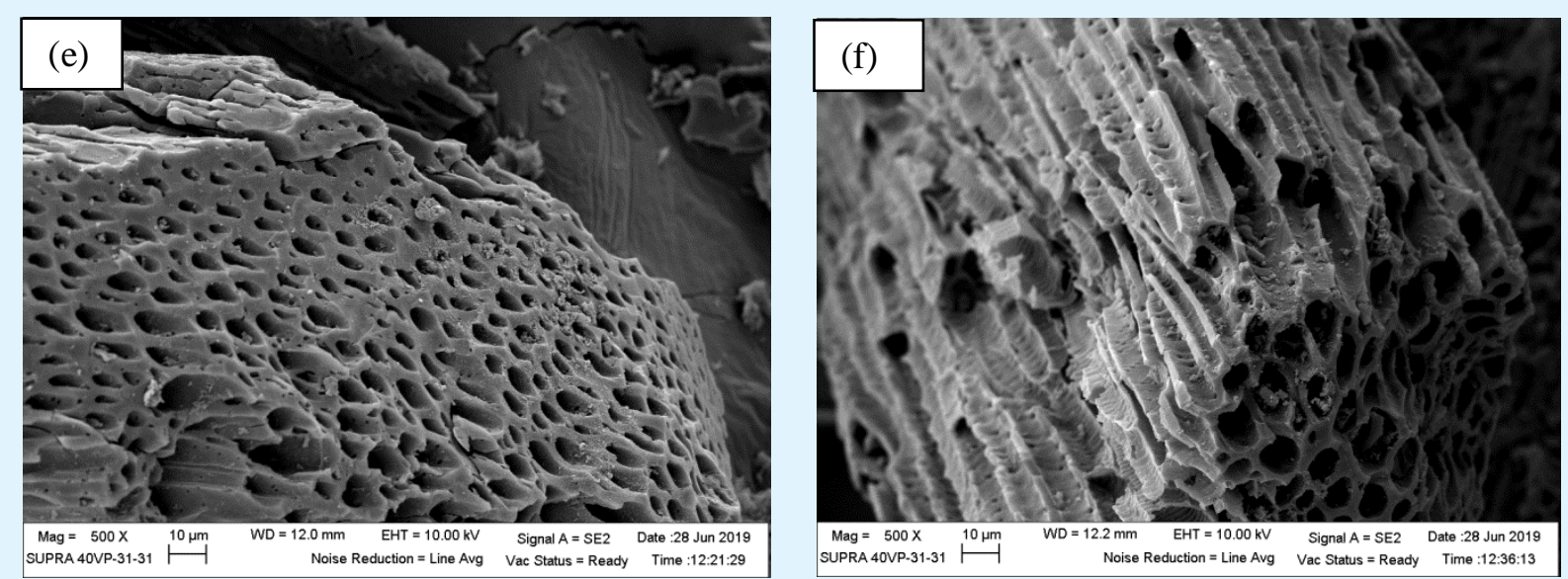

Figure 1: FESEM images of (a) non treated AC-EFB, KOH treated (b) AC-EFB (1:1 w/w), (c) AC/ $\mathrm{MoO}_{3}(5 \%),(d)$ $\mathrm{AC} / \mathrm{MoO}_{3}(10 \%)$, (e) $\mathrm{AC} / \mathrm{MoO}_{3}(15 \%)$ and (f) $\mathrm{AC} / \mathrm{MoO}_{3}(20 \%)$ with $500 \times$ magnification.

To determine the success of Mo impregnation, the prepared catalyst was qualitatively characterized using XRD. Through the XRD pattern recorded, there was obvious appearance of several peaks at $2 \theta$ of $25^{\circ}\left(\begin{array}{lll}2 & 0 & 0\end{array}\right)$, $32^{\circ}\left(\begin{array}{lll}0 & 0 & 2\end{array}\right), 37^{\circ}\left(\begin{array}{lll}0 & 2 & 1\end{array}\right), 45^{\circ}\left(\begin{array}{lll}3 & 1 & 1\end{array}\right)$ and $51^{\circ}\left(\begin{array}{lll}4 & 0 & 0\end{array}\right)$ when $\mathrm{MoO}_{3}$ was incorporated onto the AC-EFB support. These peaks were corresponds to $\mathrm{MoO}_{3}$ according to JCPDS (file number: 00-047-1081). Moreover, there was an ascending in intensity of $\mathrm{MoO}_{3}$ peaks as the weight percent of the impregnated metal increased. Another study conducted [27] where $\mathrm{MoO}_{3}$ was incorporated onto MCM-41 shares similar planes of Mo with the current study conducted.

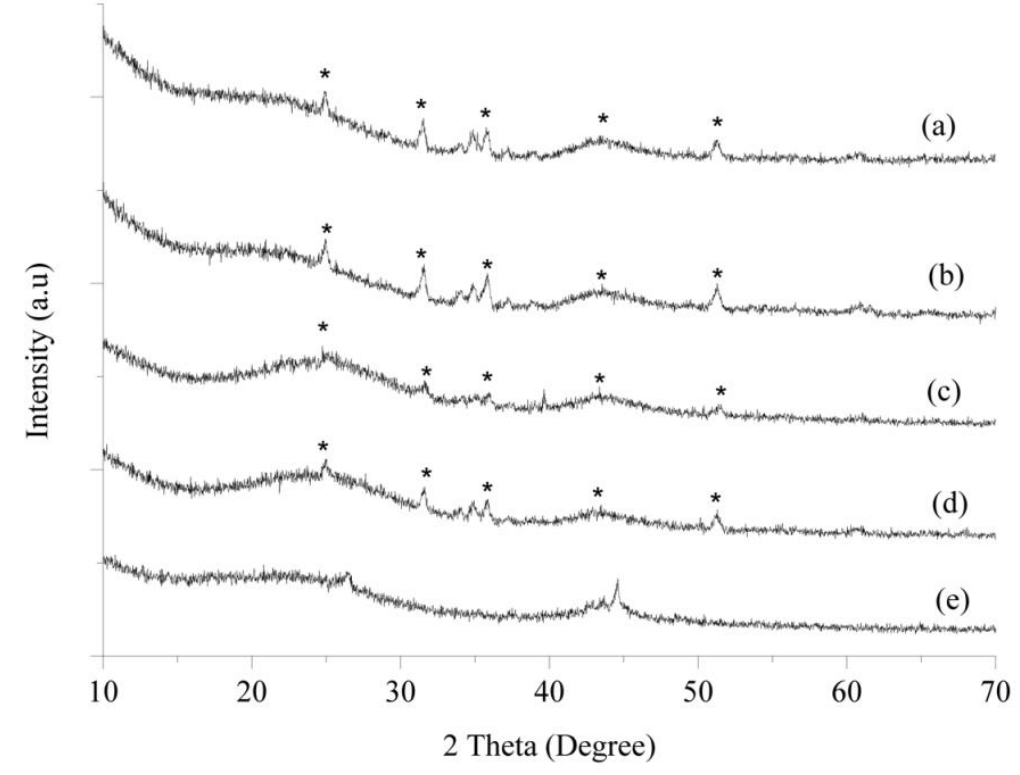

Figure 2: $\mathrm{XRD}$ diffractogram of $\mathrm{AC} / \mathrm{MoO}_{3}$ with different $\mathrm{MoO}_{3}$ loading (a) $20 \% \mathrm{MoO}_{3}$, (b) $15 \% \mathrm{MoO}_{3}$, (c) $10 \% \mathrm{MoO}_{3}$, (d) $5 \% \mathrm{MoO}_{3}$ and (e) AC-EFB. 


\section{Petroleum \& Petrochemical Engineering Journal}

Further characterization using XRF was performed to quantify the actual amount of the Mo impregnated on the AC-EFB support as shown in Table 1. Based on analysis result, the highest concentration of Mo detected was $590.6 \mathrm{ppm}$ equivalent to $0.59 \mathrm{mg} \mathrm{Mo} / \mathrm{g} \mathrm{AC}$ and lowest was
$480.7 \mathrm{ppm}$ equivalent to $0.48 \mathrm{mg} \mathrm{Mo} / \mathrm{g}$ AC for the $\mathrm{AC} / \mathrm{MoO}_{3}$ (20\%) and $\mathrm{AC} / \mathrm{MoO}_{3}$ (5\%), respectively. Obvious increasing trend of metal loaded resulting higher concentration of the actual impregnated $\mathrm{MoO}_{3}$.

\begin{tabular}{|c|c|c|c|}
\hline Type of catalyst & Concentration of Mo (ppm) & Percentage of Mo (\%) & $\begin{array}{c}\text { Mass of Mo } \\
\text { (mg Mo/g AC) }\end{array}$ \\
\hline $\mathrm{AC} / \mathrm{MoO}_{3} 5 \%$ & 480.7 & 0.48 & 0.48 \\
\hline $\mathrm{AC} / \mathrm{MoO}_{3} 10 \%$ & 513.3 & 0.51 & 0.51 \\
\hline $\mathrm{AC} / \mathrm{MoO}_{3} 15 \%$ & 563.1 & 0.56 & 0.56 \\
\hline $\mathrm{AC} / \mathrm{MoO}_{3} 20 \%$ & 590.6 & 0.59 & 0.59 \\
\hline
\end{tabular}

Table 1: Concentration of $\mathrm{Mo}$ on the $\mathrm{AC} / \mathrm{MoO}_{3}$ catalysts.

Furthermore, Table 2 summarizes the surface area, pore volume and pore size of the prepared AC with comparison to another synthesized AC from previous reported study. The carbonized EFB has the largest pore size of $8.04 \mathrm{~nm}$ yet have the least surface area $7.90 \mathrm{~m}^{2} \mathrm{~g}^{-1}$ and pore volume $0.0158 \mathrm{~cm}^{3} \mathrm{~g}^{-1}$ compared to the nontreated AC-EFB of $614.59 \mathrm{~m}^{2} \mathrm{~g}^{-1}$ and $2.0686 \mathrm{~cm}^{3} \mathrm{~g}^{-1}$ respectively. It was observed that, the dry chemical treatment applied in this work was successfully carried out, as a result the surface area from raw to calcined without chemical treatment and chemically treated was improved significantly from $7.90 \mathrm{~m}^{2} \mathrm{~g}^{-1}$ to $614.59 \mathrm{~m}^{2} \mathrm{~g}^{-1}$ and further increased to $1575.50 \mathrm{~m}^{2} \mathrm{~g}^{-1}$, respectively. As compare to the other study on AC derived EFB stated in Table 2, the current study shows higher BET aspects. This proves the proposed technique has increased the porosity of the AC derived EFB. However, the catalyst prepared shows a decrease in the surface area and pore volume for the impregnated $\mathrm{AC}$ with $\mathrm{MoO}_{3}$, where, more impregnation of metal oxides reducing the surface area and thus indicated the successful dispersion of $\mathrm{MoO}_{3}$ on the AC-EFB support.

\begin{tabular}{|c|c|c|c|c|}
\hline Catalyst & Surface area, $S_{\mathrm{BET}},\left(\mathrm{m}^{2} \mathrm{~g}^{-1}\right)$ & Pore Volume, $\left(\mathrm{cm}^{3} \mathrm{~g}^{-1}\right)$ & Pore Size, (nm) & Reference \\
\hline Raw EFB & 7.8959 & 0.015871 & 8.0403 & In this work \\
\hline $\begin{array}{c}\text { Non treated } \\
\text { AC-EFB }\end{array}$ & 614.59 & 0.3178 & 2.0686 & In this work \\
\hline $\begin{array}{c}\text { Treated } \\
\text { AC-EFB* }\end{array}$ & 1575.5 & 0.8347 & 2.1192 & In this work \\
\hline $\mathrm{AC} / \mathrm{MoO}_{3} 5 \%$ & 1350.20 & 0.7558 & 2.2392 & In this work \\
\hline $\mathrm{AC} / \mathrm{MoO}_{3} 10 \%$ & 1322.00 & 0.7164 & 2.1675 & In this work \\
\hline $\mathrm{AC} / \mathrm{MoO}_{3} 15 \%$ & 1314.30 & 0.7315 & 2.2262 & In this work \\
\hline $\mathrm{AC} / \mathrm{MoO}_{3} 20 \%$ & 1277.90 & 0.7411 & 2.3196 & In this work \\
\hline AC-EFB & 720.00 & 0.341 & - & [30] \\
\hline AC-EFB & 36.64 & - & 5.76 & [31] \\
\hline AC-EFB clinker & 2.48 & 0.0038 & - & [32] \\
\hline
\end{tabular}

*treated with $\mathrm{KOH}(1: 1 \mathrm{w} / \mathrm{w})$

Table 2: Surface characteristics of prepared AC of non-treated and chemically treated with $\mathrm{KOH}, \mathrm{AC} / \mathrm{MoO}_{3}$ with different metal loadings and other studies.

Figure 3 illustrates the $\mathrm{N}_{2}$ adsorption-desorption isotherm graph of the carbonized EFB, non-treated and treated $\mathrm{AC}$-EFB and $\mathrm{AC} / \mathrm{MoO}_{3}(5 \%)$. In accordance of the IUPAC classification, (a) was a nonporous which confirms the morphological data where the pores observed was small compared to the treated AC-EFB. In the other hand, Figure 3(b), (c) and (d) exhibit type-II isotherm, which was macro-porous, at the beginning of the almost linear middle section of the isotherm indicated that the stage at which monolayer coverage was complete and multilayer adsorption about to begin. The trends were aligned with the FESEM images which pore enlargement and thinning of the AC wall were observed. 


\section{Petroleum \& Petrochemical Engineering Journal}

(a)

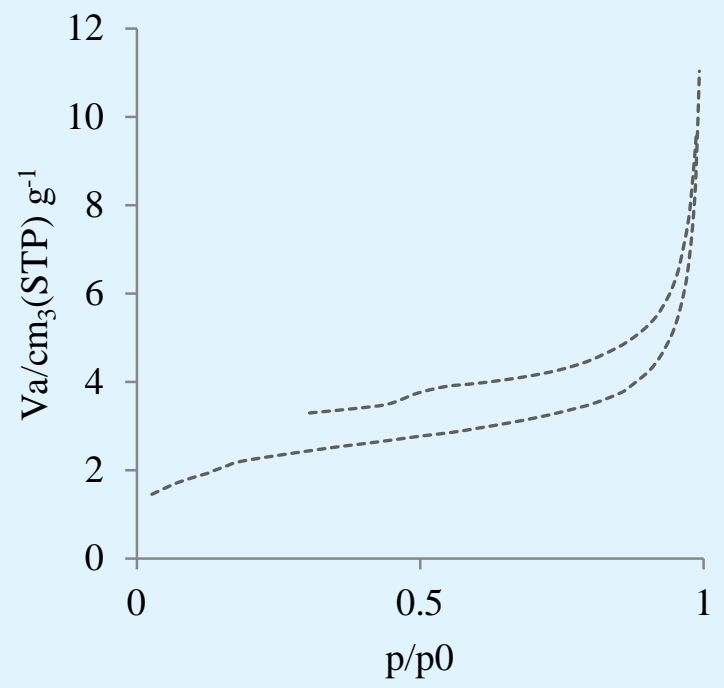

(c)

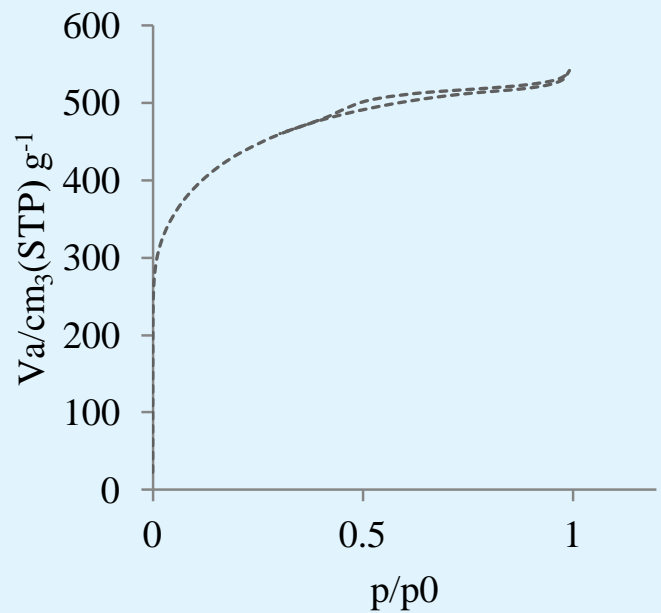

(b)

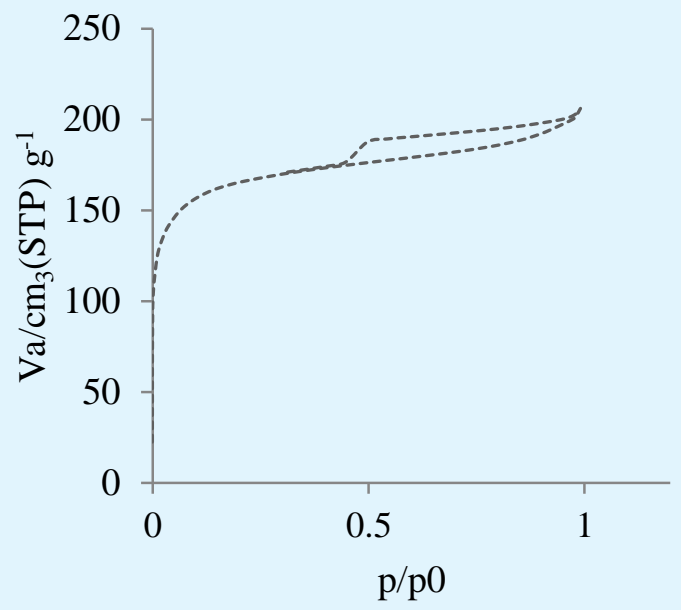

(d)

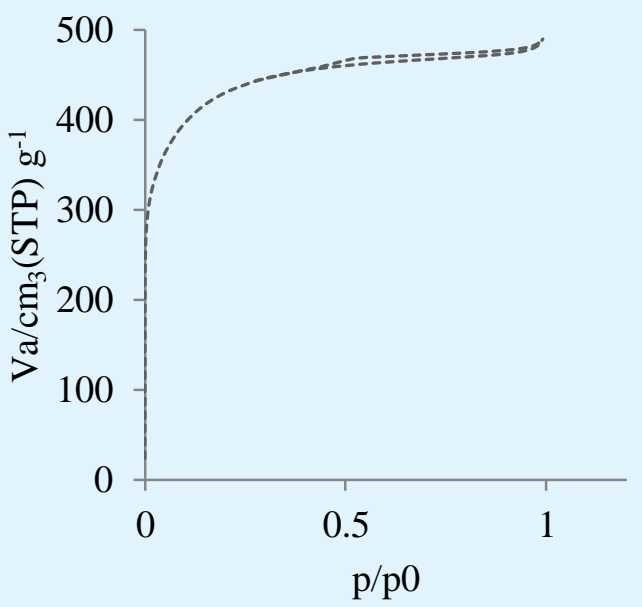

Figure 3: $\mathrm{N}_{2}$ Adsorption-isotherm graph of (a) carbonized EFB, (b) non-treated AC-EFB, (c) treated AC-EFB and (d) $\mathrm{AC} / \mathrm{MoO}_{3(5 \%)}$.

\section{Desulfurization Processes}

The performance of the EFB derived activated carbon containing $\mathrm{MoO}_{3}$ was evaluated through the removal of sulfur compound from model oil, which has been divided into two techniques known as absorption and oxidativeextractive desulfurization processes.

\section{Absorption Activity of Activated Carbon on Sulfur Removal}

In order to study the absorption performance of the AC-EFB, the prepared catalysts without any implementation of oxidant or extractant were employed into the desulfurization process for 30 minutes of vigorous stirring in $500 \mathrm{ppm}$ and $800 \mathrm{ppm}$ of DBT (sulfur compound) in model oil, and the data was presented in Figure 4. For 500 ppm sulfur, the highest removal was $60.7 \%$ using $\mathrm{AC} / \mathrm{MoO}_{3}(20 \%)$, followed by $\mathrm{AC}$ with $60.9 \%$ and $57.2 \%$ by $\mathrm{AC} / \mathrm{MoO}_{3}(5 \%)$. 


\section{Petroleum \& Petrochemical Engineering Journal}

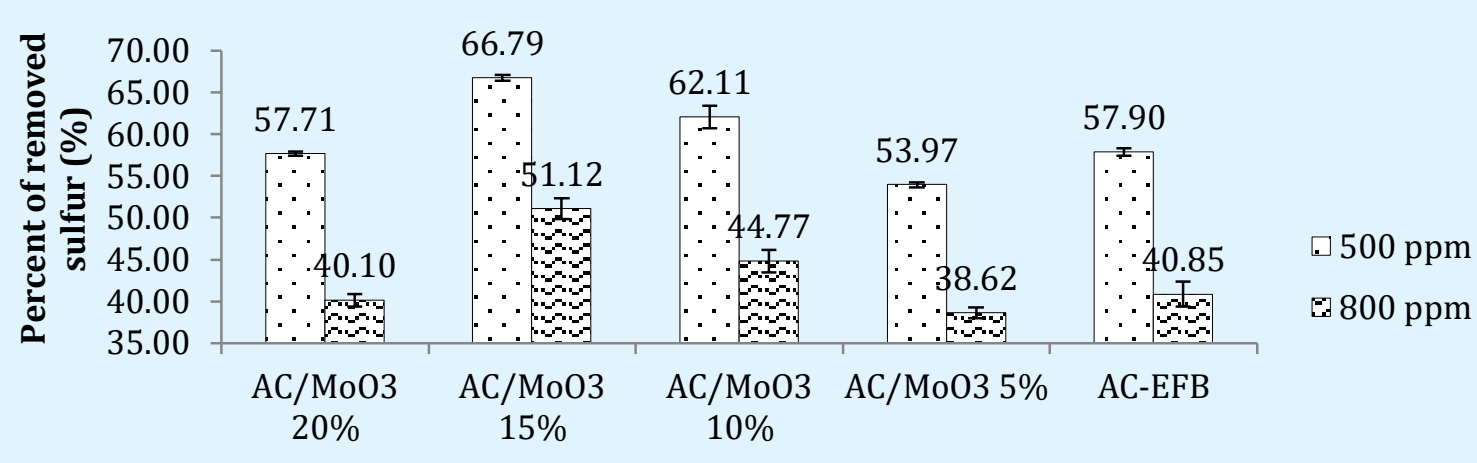

Types of catalyst

Figure 4: Adsorption of $500 \mathrm{ppm}$ and $800 \mathrm{ppm}$ of DBT using $\mathrm{Ac} / \mathrm{MoO}_{3} 20 \%, \mathrm{Ac} / \mathrm{MoO}_{3}(15 \%), \mathrm{Ac} / \mathrm{MoO}_{3}(10 \%)$, $\mathrm{Ac} / \mathrm{MoO}_{3}(5 \%)$ and treated $\mathrm{AC}$. (Parameter condition: stirring speed $500 \mathrm{rpm}$, absorption time of $30 \mathrm{~min}$ and $1 \%$ catalyst $(0.1 \mathrm{~g} / 10 \mathrm{~mL}))$.

For $800 \mathrm{ppm}$ of sulfur, the AC successfully removes highest amount of sulfur about $42.1 \%$, followed by $\mathrm{AC} / \mathrm{MoO}_{3}(20 \%)$ and $\mathrm{AC} / \mathrm{MoO}_{3}(5 \%)$ with $41.4 \%$ and $40 \%$ respectively. Furthermore, the data collected shows that there was no significant difference of sulfur removal among the $\mathrm{AC}$ and Mo impregnated AC. Even though $\mathrm{MoO}_{3}$ has a tendency as the absorption affinity, yet, the surface area of the AC was higher as compared to other impregnated $\mathrm{AC}$ with metal oxide, thus increasing the absorption of the sulfur compound.

\section{Effect of Molybdenum Oxide on Sulfur Removal}

In order to maximize the desulfurization efficiency, oxidative-extraction desulfurization was applied onto 500 ppm and 800 ppm DBT in model oil with the addition of oxidant and extractant under vigorous stirring speed at $500 \mathrm{rpm}$, at $60^{\circ} \mathrm{C}$ for oxidation process and 30 minutes of contact time followed by extraction process at room temperature. Figure 5 shows the percentage of sulfur removal using $\mathrm{AC} / \mathrm{MoO}_{3}$ (20\%), $\mathrm{AC} / \mathrm{MoO}_{3}$ (15\%), $\mathrm{AC} / \mathrm{MoO}_{3}(10 \%), \mathrm{AC} / \mathrm{MoO}_{3}(5 \%)$ and $\mathrm{AC}$. As a result, both $500 \mathrm{ppm}$ and $800 \mathrm{ppm}$ successfully exceeded $95 \%$ sulfur removal of highest $98.1 \%$ and $96.7 \%$ respectively. There was a quite huge difference in sulfur removal comparing to the process without applying oxidant and extractant.

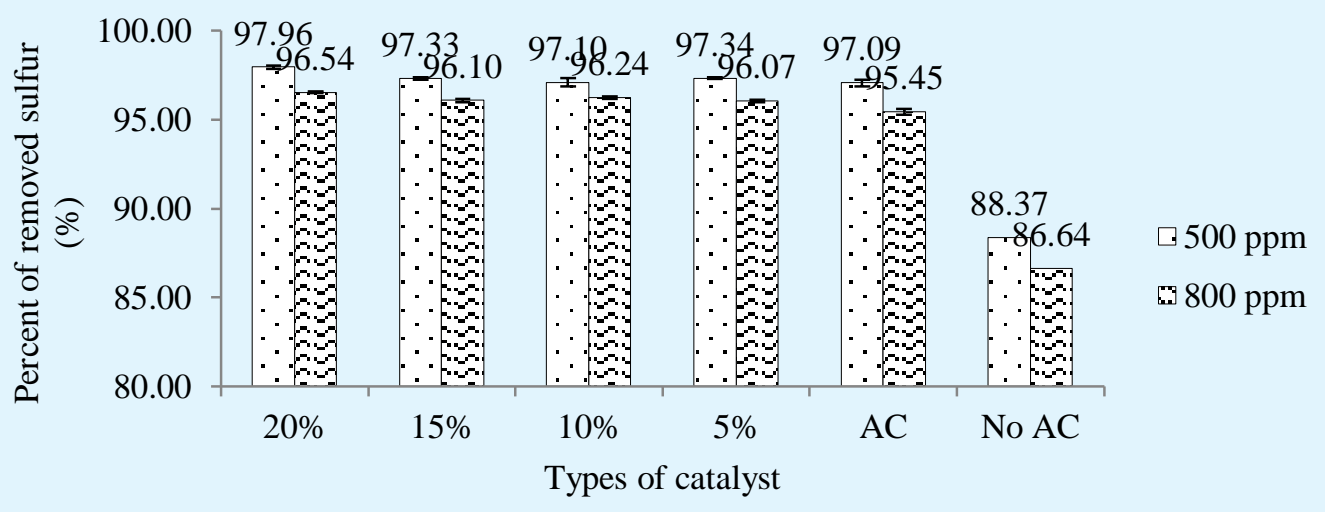

Figure 5: Oxidation extraction of DBT of $500 \mathrm{ppm}$ and $800 \mathrm{ppm}$ using $\mathrm{Ac} / \mathrm{MoO}_{3} 20 \%$, $\mathrm{Ac} / \mathrm{MoO}_{3} 15 \%$, $\mathrm{Ac} / \mathrm{MoO}_{3} 10 \%$, $\mathrm{Ac} / \mathrm{MoO}_{3} 5 \%$ and treated $\mathrm{AC}$ (parameter condition: Oxidant : sulfur $3: 1$ molar ratio, oxidation at $50^{\circ} \mathrm{C}$, catalyst $0.1 \mathrm{~g}$, extraction at room temperature, extractant to oil 1:1 volume ratio). 


\section{Petroleum \& Petrochemical Engineering Journal}

However, only slight increment was observed when the $\mathrm{MoO}_{3}$ impregnated $\mathrm{AC}$ is used to improve the efficiency of the desulfurization process. Theoretically, the metal oxide will initiate the oxidation process of DBT to sulfone. However, may be due to the small amount of metal oxides presence on the structure (Table 1) could not maximize the rate of desulfurization process. However, the simultaneous absorption-oxidationextraction process assisted by $\mathrm{AC} / \mathrm{MoO}_{3}$ showed remarkable removal of sulfur compound up to $97.9 \%$. This might be due to the interaction of oxidant TBHP and catalyst $\mathrm{MoO}_{3}$ which initially form peroxidic complex and oxidizes the DBT to form DBT sulfoxide (intermediate) and further oxidized by another peroxidic complex to form DBT sulfone [33].

\section{Conclusion}

The evaluation on the capability of the value-added EFB as a catalyst support was successfully carried out. Treatment of carbonized EFB with $\mathrm{KOH}$ successfully improves the surface characteristics by increasing the surface area and pore sizes, which experimentally increased the absorption affinity toward sulfur compound. The results showed that the presence of impregnated $\mathrm{MoO}_{3}$ on $\mathrm{AC}$ derived EFB, oxidant TBHP and extractant DMF had successfully increased the desulfurization up to $97.9 \%$, as compared to the normal absorption process only $66.8 \%$. This can be concluded that the $\mathrm{MoO}_{3}$ impregnated AC derived EFB has catalyzed the absorption-oxidation-extraction process effectively and has high potential for the sulfur removal from sulfurcontained fuels.

\section{Acknowledgement}

The author would like to acknowledge the Universiti Teknologi MARA Malaysia for the research funds; LESTARI research grant 600-IRMI/MYRA 5/3/LESTARI $(054 / 2017)$ and BESTARI research grant 600IRMI/PERDANA 5/3 BESTARI (088/2018). Special thanks to Institute of Science, Universiti Teknologi MARA and Catalysis Science \& Technology Research Centre, Universiti Putra Malaysia for all the facilities provided throughout this work.

\section{References}

1. Echols KR, Meadows JC, Orazio CE (2009) Pollution of Aquatic Ecosystems II: Hydrocarbons, Synthetic Organics, Radionuclides, Heavy Metals, Acids, and
Thermal Pollution. Encyclopedia of Inland Waters, pp: 120-128.

2. Kropp KG, Andersson JT, Fedorak PM (1997) Bacterial transformations of 1,2,3,4tetrahydrodibenzothiophene and dibenzothiophene. Applied Environment Microbiol 63(8): 3032-3042.

3. William Leffler (2008) Petroleum Refining in Nontechnical Language. $4^{\text {th }}(E d n$.$) , PennWell Corp,$ Oklahoma, USA.

4. Mariano JB (2005) Impactos Ambientais do Refino de

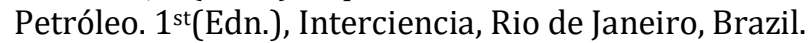

5. Saleh A (2018) Simultaneous adsorptive desulfurizati on of diesel fuel over bimetallic nanoparticles loaded on activated carbon. Journal of Cleaner Production 172: 2123-2132.

6. Saleh TA, Al-hammadi SA, Tanimu A, Alhooshani K (2018) Ultra-deep adsorptive desulfurization of fuels on cobalt and molybdenum nanoparticles loaded on activated carbon derived from waste rubber. J Colloid Interface Sci 513: 779-787.

7. Gao S, Li J, Chen X, Abdeltawab, AA, Yakout SM (2018) A combination desulfurization method for diesel fuel : Oxidation by ionic liquid with extraction by solvent. Fuel 224: 545-551.

8. Rangra S, Kabra M, Gupta V, Srivastava P (2018) Improved conversion of Dibenzothiophene into sulfone by surface display of Dibenzothiophene monooxygenase (DszC) in recombinant Escherichia coli. J Biotechnol 287: 59-67.

9. Kang M, Wang X, Zhang J, Lu Y, Chen X, Yang L, Wang F (2019) Boosting the photocatalytic oxidative desulfurization of dibenzothiophene by decoration of $\mathrm{MWO}_{4}(\mathrm{M}=\mathrm{Cu}, \mathrm{Zn}, \mathrm{Ni})$ on $\mathrm{WO}_{3}$. Journal of Environmental Chemical Engineering 7(1): 102809.

10. Al-hammadi SA, Al-Amer AM, Saleh A (2018) Alumina-carbon nanofiber composite as a support for MoCo catalysts in hydrodesulfurization reactions. Chemical Engineering Journal 345: 242-251.

11. Sikarwar P, Arun Kumar UK, Gosu V, Subbaramaiah V (2018) Catalytic oxidative desulfurization of DBT using green catalyst (Mo / MCM- 41) derived from coal fly ash. Journal of Environmental Chemical Engineering 6(2): 1736-1744. 


\section{Petroleum \& Petrochemical Engineering Journal}

12. Akhtar N, Akhtar K, Ghauri MA (2017) Biodesulfurization of Thiophenic Compounds by a 2 Hydroxybiphenyl Resistant Gordonia sp. HS126-4N Carrying dszABC Genes. Curr Microbiol 75(5): 597603.

13. Contreras-Valdez Z, Mogica-Betancourt JC, AlvarezHernandez A, Guevara-Lara A (2013) Solvent effects on dibenzothiophene hydrodesulfurization: differences between reactions in

14. Rodriguez-Castellon E, Jimenez-Lopez A, ElicheQuesada D (2008) Nickel and cobalt

15. Mello MISDe, Sobrinho EV, Victor LST, Pergher SBC (2 018) $\mathrm{V}$ or $\mathrm{Mn} \quad$ zeolite catalysts for the oxidative desulfurization of diesel fractions using dibenzothiophene as a probe molecule: Preliminary study. Molecular Catalysis pp: 2468-8231.

16. Wang Y, Dai L, Fan L, Duan D, Liu Y, et al. (2017) Microwave-assisted catalytic fast co-pyrolysis of bamboo sawdust and waste tire for bio-oil production. Journal of Analytical and Applied Pyrolysis 123: 224-228.

17. Saleh TA, Danmaliki GI (2016) Adsorptive desulfurization of dibenzothiophene from fuels by rubber tyres derived carbons: Kinetics and isotherms evaluation. Process Safety and Environmental Protection 102: 9-19.

18. Subbaramaiah V, Srivastava V, Deo Mall I (2013) Optimization of Reaction Parameters and Kinetic Modeling of Catalytic Wet Peroxidation of Picoline by Cu/SBA-15. Ind Eng Chem Res 52(26): 9021-9029.

19. Abdullah A Al, Saleh A, Ganiyu SA, Siddiqui MN (2017) Preparation of activated carbon, zinc oxide and nickel oxide composites for potential application in the desulfurization of model diesel fuels. Journal of Analytical and Applied Pyrolysis 128: 246-256.

20. Dorneles M, Mello D, Almeida FDe, Magalhaes C (2018 ) Kinetic modeling of deep hydrodesulfurization of dibenzothiophenes on NiMo/alumina catalysts modified by Phosphorus. Fuel Processing Technology 177: 66-74.

21. Li S, Li J, Gao Y, Liang L, Zhang R, et al. (2017) Metal modified heteropolyacid incorporated into porous materials for a highly oxidative desulfurization of DBT under molecular oxygen. Fuel 197: 551-561.
22. Mansouri A, Semagina N (2017) Enhancement of palladium-catalyzed direct desulfurization by yttrium addition. Applied Catalysis A: General 543: 43-50.

23. Mendez FJ, Bravo-ascención G, González-mota M, Puente-lee I (2018) NiMo catalysts supported on Al, $\mathrm{Nb}$, Ti or Zr-containing MCM-41 for dibenzothiophene hydrodesulfurization. Catalysis Today.

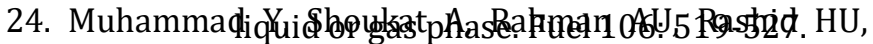
Ahmad W (2018) Oxidative desulfurization of dibenzothiophene over Fe promoted $\mathrm{CoMo} / \mathrm{Al}_{2} \mathrm{O}_{3}$ and

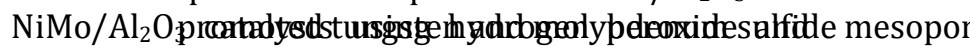
formic acid as oxidants. Chinese Journal of Chemical Engineering 26(3): 593-600.

25. Run-dong D, Yun ZU, Chuan-hang Z, Huan W, Zhousheng MO (2018) Insight in the

26. Shen D, Dai Y, Han J, Gan L, Liu J, Long M (2018) A nanocellulose template strategy for the controllable synthesis of tungsten- containing mesoporous silica for ultra-deep oxidative desulfurization. Chemical Engineering Journal 332: 563-571.

27. Teimouri A, Mahmoudsalehi M, Salavati H (2018) Cat alytic oxidative desulfurization of dibenzothiophene $u$ tilizing molybdenum and vanadium oxides supported on MCM-41. International Journal of Hydrogen Energy 43(31): 1-18.

28. Abdullah WNW, Bakar WAWA, Ali R, Mokhtar WNAW, Omar MF (2017) Catalytic oxidative desulfurization technology of supported ceria based catalyst: Physicochemical and mechanistic studies. Journal of Cleaner Production 162: 1455-1464.

29. Wang J, Kaskel S (2012) KOH activation of carbonbased materials for energy storage. Journal Material Chemistry 22(45): 23710-23725.

30. Hidayu AR, Mohamad NF, Matali S, Sharifah ASAK (2013) Characterization of Activated Carbon Prepared from Oil Palm Empty Fruit Bunch Using BET and FT-IR Techniques. Procedia Engineering 68: 379384.

31. Ibrahim NA, Rashid U, Taufiq-Yap YH, Yaw TCS, Ismail I (2019) Synthesis of carbonaceous solid acid magnetic catalyst from empty fruit bunch for esterification of palm fatty acid distillate (PFAD). Energy Conversion and Management 195: 480-491. 


\section{Petroleum \& Petrochemical Engineering Journal}

32. Cheng CK, Chan HJ (2016) Potential of empty fruit bunch clinker as a support for nickel and cobalt catalysts in methane dry reforming: waste to wealth approach. Journal of the Taiwan Institute of Chemical Engineers 62: 76-83.
33. Ishihara A, Wang D, Dumeignil F, Amano H, Qian E, et al. (2005) Oxidative desulfurization and denitrogenation of a light gas oil using an oxidation/adsorption continuous flow process. Applied Catalysis A: General 279(1-2): 279-287. 